\title{
Two- to 4-Year Followup of a Short Stem THA Construct: Excellent Fixation, Thigh Pain a Concern
}

\author{
Richard L. Amendola MS, Devon D. Goetz MD, Steve S. Liu MD, \\ John J. Callaghan MD
}

Published online: 14 July 2016

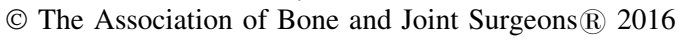

\begin{abstract}
Background Short stem cementless femoral components were developed to aid insertion through smaller incisions, preserve metaphyseal bone, and potentially decrease or limit the incidence of thigh pain. Despite some clinical success, the senior author (DDG) believed a higher percentage of his patients who had received a cementless short stem design were experiencing thigh pain, which, coupled with concerns about bone ingrowth fixation, motivated the review of this case series.
\end{abstract}

One of the authors (JJC), or a member of his or her immediate family, has or may receive payments or benefits, during the study period, an amount more than USD 1,000,001 from DePuy (Warsaw, IN, USA); and received royalties for books edited from Wolters Kluwer (Baltimore, MD, USA).

All ICMJE Conflict of Interest Forms for authors and Clinical Orthopaedics and Related Research ${ }^{\mathbb{R}}$ editors and board members are on file with the publication and can be viewed on request.

Clinical Orthopaedics and Related Research ${ }^{\mathbb{B}}$ neither advocates nor endorses the use of any treatment, drug, or device. Readers are encouraged to always seek additional information, including FDAapproval status, of any drug or device prior to clinical use.

Each author certifies that his or her institution approved the human protocol for this investigation, that all investigations were conducted in conformity with ethical principles of research, and that informed consent for participation in the study was obtained.

This work was performed at Des Moines Orthopaedic Surgeons, West Des Moines, IA, USA, and the University of Iowa, Iowa City, IA, USA.

R. L. Amendola ( $₫)$, S. S. Liu, J. J. Callaghan

Department of Orthopaedics, University of Iowa, 200 Hawkins

Drive, UIHC, Iowa City, IA 52242, USA

e-mail: richard-amendola@uiowa.edu

D. D. Goetz

Des Moines Orthopaedic Surgeons, West Des Moines, IA, USA
Questions/purposes (1) What is the proportion of patients treated with a short stem cementless THA femoral component that develop thigh pain and what are the hip scores of this population? (2) What are the radiographic results, specifically with respect to bone ingrowth fixation and stress shielding, of this design? (3) Are there particular patient or procedural factors that are associated with thigh pain with this short stem design?

Methods Two hundred sixty-one primary THAs were performed in 238 patients by one surgeon between November 2010 and August 2012. During this time period, all patients undergoing primary THA by this surgeon received the same cementless short titanium taper stem. Seven patients (eight hips) died and five patients (five hips) were lost to followup, leaving 226 patients (248 hips) with a mean followup of 3 years (range, 2-5 years). Patients rated their thigh pain during activity or rest at final followup on a 10-point visual analog scale. Harris hip scores (HHS) were obtained at every clinic appointment. Thigh pain was evaluated at the final followup or by contacting the patient by phone. Radiographs were evaluated for boneimplant fixation, bone remodeling, and osteolysis. An attempt was made to correlate thigh pain with patient demographics, implant specifications, or radiographic findings.

Results Seventy-six percent of hips (180 of 238) had no thigh pain, $16 \%$ of hips ( 37 of 238 ) had mild thigh pain, and $9 \%$ (21 of 238) had moderate or severe thigh pain. Preoperatively, mean HHS was 47 (SD, 16) and at last followup, mean HHS was 88 (SD, 13). There were two femoral revisions, one for severe thigh pain and the other for infection. All but two components demonstrated bone ingrowth fixation (99\%). Femoral stress shielding was mild in $64 \%$ of hips (135 of 212), moderate in $0.5 \%$ (one of 212), and severe in no hips. There is an inverse linear 
relationship between age and severity of thigh pain ( $\mathrm{r}=-0.196 ; \mathrm{p}<0.0024)$.

Conclusions Although reliable fixation was achieved and good HHS were attained, the frequency and severity of thigh pain with this short cementless stem were concerning. The surgeon has subsequently abandoned this short stem design and returned to a conventional length stem. Future study direction might investigate the biomechanical grounds for the thigh pain associated with this stem design. Level of Evidence Level IV, therapeutic study.

\section{Introduction}

Conventional length cementless THA is an established treatment for end-stage arthritis of the hip. THA is now a viable option for younger, active, patients and those with a high body mass index [1]. With this population, effective THA requires preservation of the metaphyseal bone, effective femoral revision options, and easier insertion options through less invasive approaches [18, 27, 36, 45]. Short stem cementless femoral components were developed to preserve metaphyseal bone after THA through proximal load transfer. In addition, shorter broach-only stems can provide easier insertion, especially through smaller direct anterior approaches [18, 27, 36, 45]. Earlier studies have shown that short stems have similar risks of revision as well as comparable fixation and clinical outcomes to conventional length stems [2, 40, 49].

Numerous variations of short stem devices have been designed [11]. Despite increased use of short femoral stems and excellent short- to midterm results, there are still relatively little data on individual short stem designs [49]. It is remains unclear whether all cementless short femoral stem designs are able to achieve comparable long-term clinical results to traditional stems while also achieving the goals of preserving metaphyseal bone and limiting thigh pain. One of the authors (DDG) began using the Tri-Lock Bone Preservation Stem (DePuy, Warsaw, IN, USA) exclusively for all primary THAs in his practice in November 2010. He observed what he believed to be increased thigh pain in these patients as well as radiographic concerns regarding bone fixation of the stem, prompting a more detailed study of this cohort.

With these observations in mind, the authors asked: (1) What is the proportion of patients treated with a short stem cementless THA femoral component that develop thigh pain and what are the hip scores of this population? (2) What are the radiographic results, specifically with respect to bone ingrowth fixation and stress shielding, of this design? (3) Are there particular patient or procedural factors that are associated with thigh pain with this short stem design?

\section{Patients and Methods}

Between November 2010 and August 2012, 261 primary THAs (238 patients) were performed by the senior author. All of those procedures used the design reviewed here and no patients undergoing primary THA were selectively treated with another design. At 2 to 4 years after the index THA, 226 patients (248 hips [95\%]) were living, seven patients (eight hips [3\%]) had died, and five patients (five hips [2\%]) were lost to followup. The stem reviewed in this study is a titanium, circumferentially proximally coated mediolateral (ML) taper short femoral stem, which was implanted with a 32- or 36-mm modular cobalt-chrome or ceramic femoral head (Fig. 1). The stem length (95$119 \mathrm{~mm}$ ) increases with ML size. The femoral component was implanted with the Pinnacle Sector 2 acetabular component (DePuy) in all hips. Highly crosslinked polyethylene (Altrex; DePuy) liners were used in all hips.

The mean age of the patients at the time of the index THA was 64 years (range, 21-91 years) and there were 104 men and 134 women. One patient had a preoperative

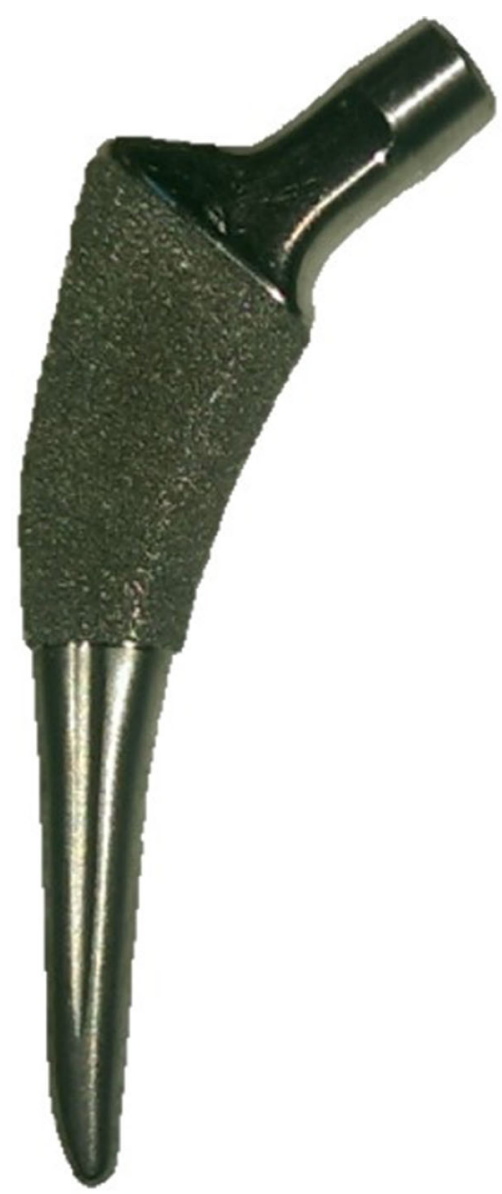

Fig. 1 This is a photograph of the Tri-Lock $(\mathbb{R})$ Bone Preservation Stem. 
diagnosis of osteonecrosis and all other patients had a preoperative diagnosis of osteoarthritis. Consent for study participation was obtained as per the protocol previously approved by the institutional review board. Mean clinical followup was 3 years (range, 2-5 years) for living patients and 3 years (range, 0.04-5 years) for the entire cohort.

All surgical procedures were performed by the author (DDG) through an anterolateral approach. The stem was inserted with a broach-only technique. For all cases, the acetabulum was reamed to $1 \mathrm{~mm}$ less than the diameter of the component used. One, two, or three 5-mm titanium alloy dome screws were used to augment fixation at the surgeon's discretion.

Patients were progressed to full weight bearing as tolerated, typically transitioning from a walker or crutches to a cane to no support over a period of 4 weeks.

An AP pelvis radiograph was obtained in the recovery room, at 6 weeks, and at 1-year followup. AP pelvis and frog leg lateral hip films were performed at 2- to 3-year intervals after the 1-year followup. Crosstable lateral radiographs were only obtained if there was concern for instability or iliopsoas tendinitis. Patients returned to the clinic for followup or, if they were unable to return, received local radiographs, which were sent to us for evaluation. Early postoperative and interval followup radiographs included AP projections of the pelvis that included the tip of the femoral prosthesis and lateral projections of the femur that included the hip.

Followup clinical evaluation of the patients included the Harris hip score (HHS) [20], a history and examination, and determination of whether future revision surgery was planned. HHS was obtained preoperatively and at every clinic visit. Patients were given the surveys over the phone or answered them alone (on paper or through the Internet). Patients were also asked if they had thigh pain at their most recent followup visit. The question did not specify whether the pain was at rest or during activity. If a patient wanted clarification on what thigh pain was, the author who administered the survey (RLA) clarified that it was pain occurring below the hip and above the knee. If they responded "yes," the followup questions asked them how often they had thigh pain (all the time, most of the time, some of the time, a little of the time, or never), a single location where the pain was located (front, side, or back), and to rate their thigh pain on a 10-point visual analog scale [3, 4]. For the HHS, a higher score reflects higher function. On the visual analog scale used for thigh pain $(0-$ 10), higher score reflects more severe pain. Radiographic observations and measurements were based on the AP radiographs from the early postoperative period and those at final followup. Among the 226 living patients not lost to followup (248 hips), 217 (88\%) hips had a minimum 2-year followup radiograph. Some patients were willing to take the survey but refused to participate in the radiographic followup. Two authors not involved in the surgery reviewed all radiographs (RLA, JJC) with interpretation reported by consensus. Correction for magnification was completed by standardizing all measurements against the known size of the femoral head. Femoral component fixation was evaluated for bone ingrowth, stable fibrous fixation, or unstable fibrous fixation according to the criteria of Engh et al. [9]. Femoral component subsidence was determined using the relationship of the top of the lesser trochanter to the medial aspect of the stem collar, defined as a decrease of at least $5 \mathrm{~mm}$ between the initial postoperative radiograph and those from final followup. Osteolysis was defined as any nonlinear radiolucency at the bone-prosthesis interface that was at least $5 \mathrm{~mm}$ according to the seven femoral zones defined by Gruen et al. [17]. Femoral component stress shielding was defined using a modification of the criteria defined by Engh and Bobyn [8]. Mild stress shielding was limited to the upper third of the implant, moderate stress shielding extended to the middle third, and severe stress shielding extended below the middle third. Acetabular components were evaluated for bone-prosthesis radiolucencies and acetabular component migration according to the criteria of Massin et al. $[12,21,28]$. The definition of acetabular osteolysis was the same as that for femoral osteolysis. Radiographic evidence of loosening was defined as definite or probable loosening, including cases revised for femoral loosening or unstable fibrous fixation.

We were interested to see if the presence and severity of thigh pain correlated with any of the patient demographics, implant specifications, HHS, or radiographic findings. Pearson correlation coefficients were calculated for continuous categories: age, body mass index, and HHS. T-tests were used to compare variables with two groups: sex, stem offset, head type (cobalt-chrome and ceramic), head diameter, and cortical hypertrophy. Analysis of variance was used for categorical variables with more than two categories: stem size, stress shielding and stem position. Probability values $<0.05$ were considered significant.

\section{Results}

A total of $16 \%$ of patients (37 hips) had mild thigh pain, $7 \%$ (16 hips) had moderate, and 2\% (five hips) had severe thigh pain (Fig. 2). Of the patients with thigh pain, $49 \%$ reported having it a little of the time, $34 \%$ reported some of the time, $14 \%$ reported most of the time, and $3 \%$ had thigh pain all the time. Forty-four percent of patients with thigh pain located the pain anteriorly, 51\% laterally, and 5\% posteriorly. Preoperatively, mean HHS was 47 (SD, 16) and at last followup, mean HHS was 88 (SD, 13). There 
were five reoperations, two for infection, two for heterotopic ossification, and one for thigh pain. One of the infections required a femoral revision. The two hips with heterotopic ossification were bilateral THAs in the same patient and neither required femoral revision. The overall proportion of femoral component revision was $0.8 \%$ (two hips).

Radiographic evaluation of the 217 hips in living patients with minimum 2-year radiographic followup (average, 3 years) demonstrated femoral bone ingrowth in 215 (99\%) hips. For the two hips that did not have bone ingrowth, both demonstrated stable fibrous ingrowth radiographically at 2.4- and 2.9-year followup. Of the seven patients (eight hips) who died before the minimum 2to 4-year followup, all stems were bone-ingrown at last followup. None of the patients who died had undergone revision surgery before their death. The patients who showed sclerosis on most recent radiographs (13 hips)

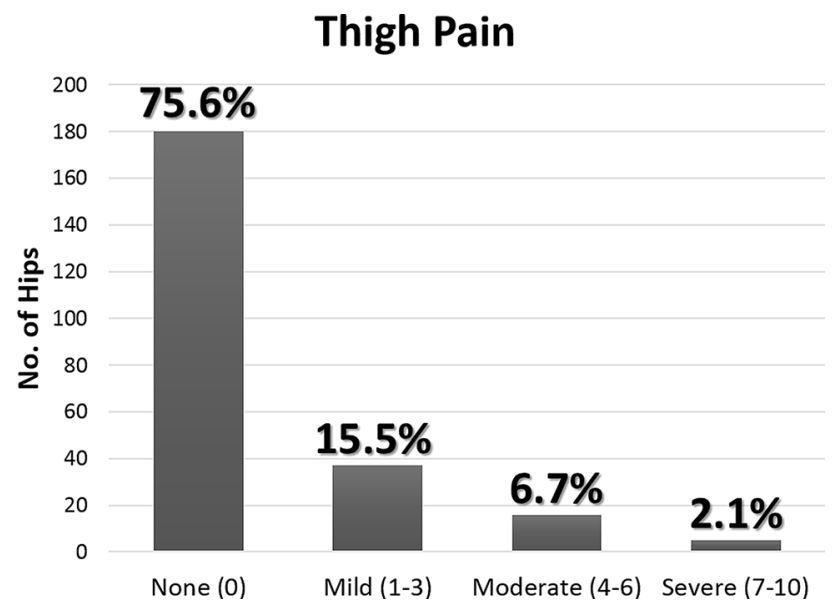

Fig. 2 Patient-reported thigh pain from the visual analog scale is shown. reported no thigh pain. The patients without sclerosis (204 hips) had a mean thigh pain of 0.38 on a scale of 0 to 10 . These groups were statistically different $(p<0.001)$. Femoral stress shielding was mild in 64\% (135 of 217 hips), moderate in $0.5 \%$ (one of 217 hips), and severe in no hips. Radiographic evaluation of the acetabular construct showed all of them to be osseointegrated (212 of $217 \mathrm{hips}$ ). Stem position was neutral in $89 \%$, varus in $8 \%$, and valgus in $2 \%$. Cortical hypertrophy was present in $2 \%$ (four hips). Of the original 248 hips, there were five reoperations.

Of the factors tested, younger age and lower HHS were correlated with increasing severity of thigh pain $(p<0.05)$. Pearson correlation coefficient for age and thigh pain showed a very weak correlation $(r=-0.196$, $\mathrm{p}=0.0024)$. Correlation coefficient for HHS was weakly correlated with thigh pain $(r=-0.39804, p<0.001)$.

\section{Discussion}

Short stem cementless femoral components were developed to preserve metaphyseal bone by proximal load transfer, simplify insertion in less invasive exposures, and potentially limit thigh pain. The use of short femoral stems has increased over the last decade [49]. Although the preservation of metaphyseal bone and ease of insertion may seem intuitive, what remains unresolved with short stem designs is whether they can achieve comparable functional and radiographic results to standard length stems in the long term and also maintain a low frequency of thigh pain. We therefore evaluated a series of patients who received one short femoral stem design in an attempt to answer these questions. Although functional and radiographic results were generally satisfactory, there was a concerning proportion of patients who reported thigh pain in our series.

Table 1. Comparison of cohort demographics

\begin{tabular}{lll}
\hline Demographic & Conventional stem* & Short stem \\
\hline Total number of patients (number of hips) & $88(100)$ & $238(261)$ \\
Average age at index surgery (years; range) & $62(25-90)$ & $64(21-91)$ \\
Sex, percent of patients (percent of hips) & Male 42 (40) & Male 44 (44) \\
& Female 58 (60) 56 (56) \\
Average body mass index $\left(\mathrm{kg} / \mathrm{m}^{2} ;\right.$ range) & $30(18-60)$ & $30(16-56)$ \\
Preoperative diagnosis, percent of hips (number of hips) & Osteoarthritis 79 (88) & Osteoarthritis 100 (260) \\
& Avascular necrosis 5 (8) & Avalar necrosis 0.4 (1) \\
& Rheumatoid arthritis 2 (2) & Protrusio 1 (1) \\
& Nonunion/malunion 1(1) &
\end{tabular}

* Goetz et al. [16]. 


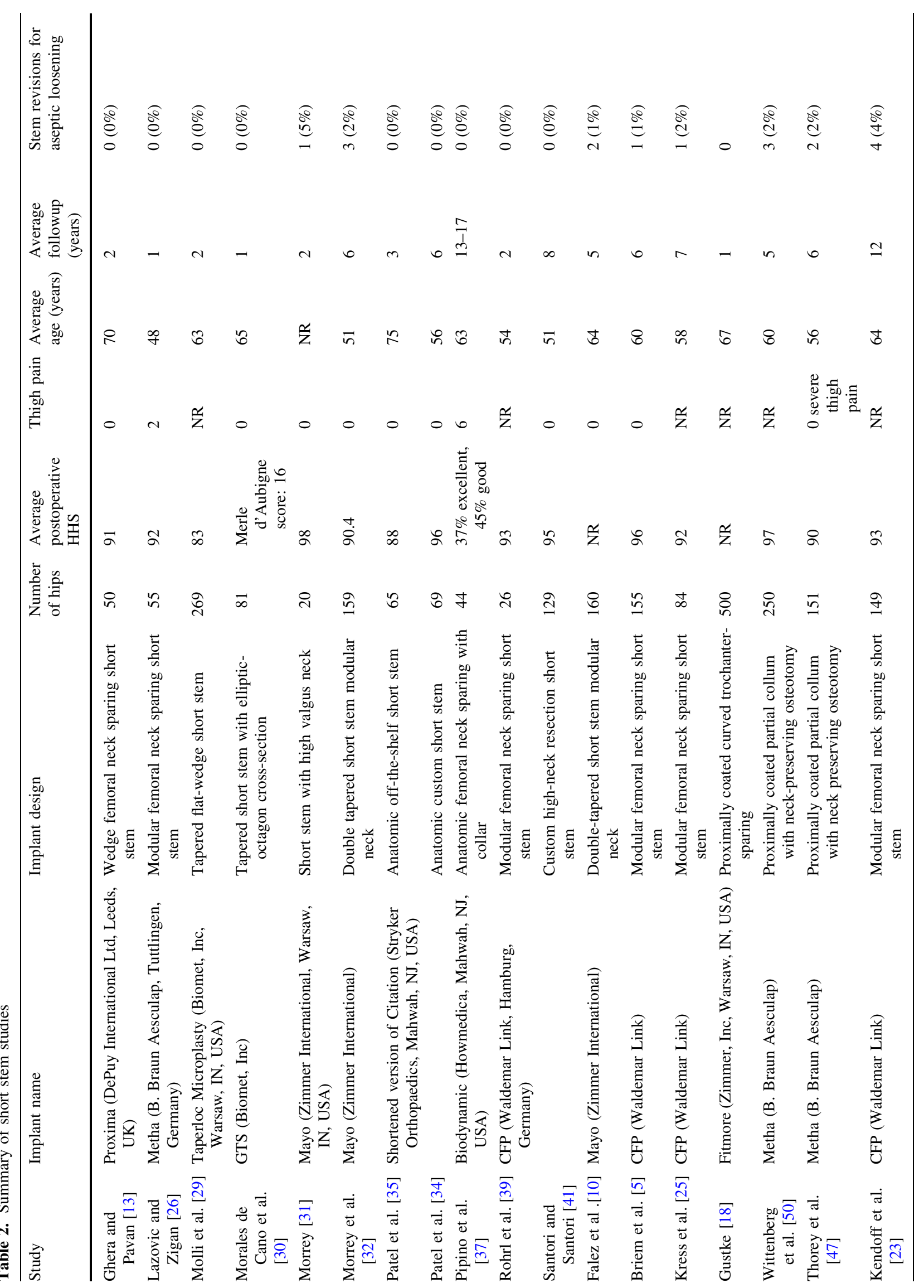




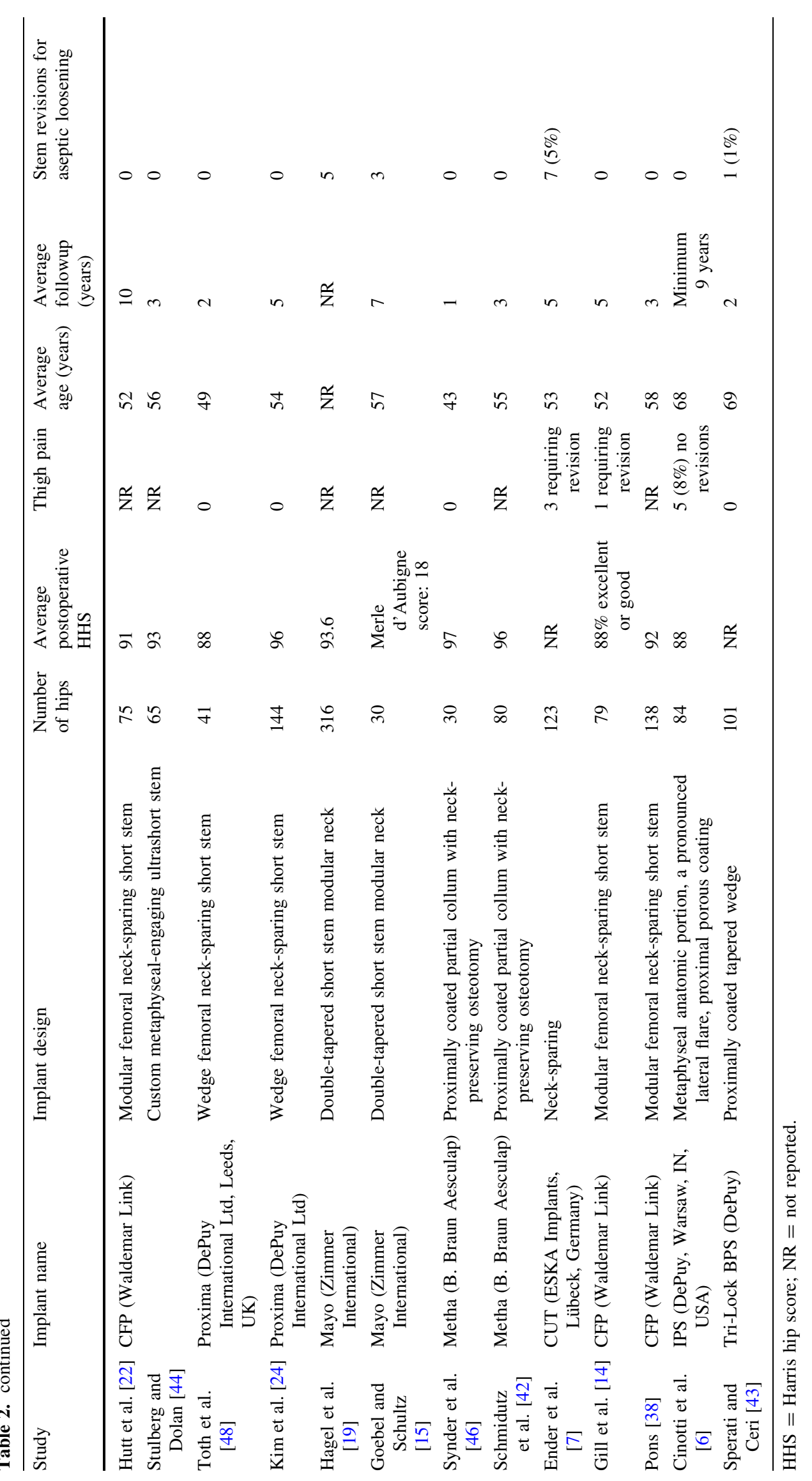



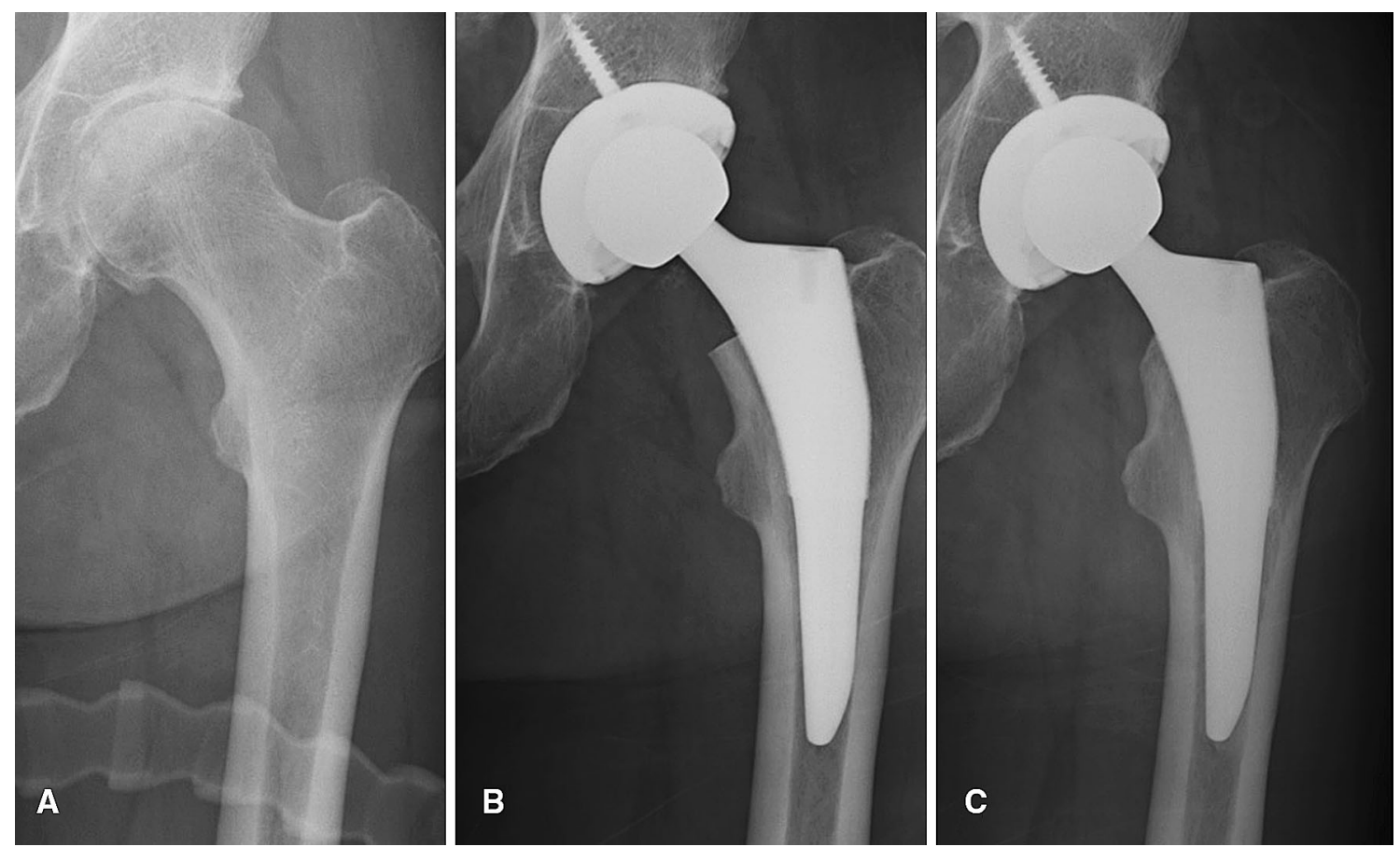

Fig. 3A-C This is an example of a 71-year-old man who underwent THA at age 68 years with the following clinical scores at most recent followup: 100, 75, and 83 on the WOMAC pain, stiffness, and function scores, respectively; a HHS of 94; SF-36 Physical and Mental scores of 52 and 62, respectively; a Tegner of 2; and a UCLA score of 6. (A) On the left is a preoperative AP radiograph. (B) A 6week postoperative AP radiograph is shown. (C) On the right is a 3year final followup AP radiograph.

including inter- and intraobserver variability of radiographic measurements. However, all radiographic findings were agreed on by two observers (JJC, RLA). We also acknowledge that determining the amount of stress shielding is somewhat problematic because of the variability of radiographic quality and observer interpretations. However, we used an established grading system that evaluates patterns of bone remodeling.

Thigh pain was substantial and moderate or severe in $9 \%$ of patients (9\% of hips) who received this stem. The same surgeon earlier reported his experience using a conventional length cementless stem [16] with similar demographics to this group (Table 1). The patient-reported frequency of moderate or severe thigh pain (21 of 238 hips [9\%]) using this short tapered stem was much greater than that reported with the standard length tapered stem (one of 100 hips [1\%]) [16]. Our reported thigh pain is also higher than that reported in another followup study using the same femoral stem by Sperati and Ceri [43]. In their observational study, they reported minimal thigh pain but no description of the data collected was given. It is unclear whether their patients were specifically queried regarding presence, location, and severity of thigh pain, which might explain the difference in findings. Only five of the studies of short stems reviewed (Table 2) reported any thigh pain 
at all $[6,7,14,26,37]$. Two studies reported thigh pain requiring revision surgery [7, 14]. Cinotti et al. reported that three of the five cases of thigh pain in their series appeared to be unrelated to the THA procedure [6]. Pipino et al. [37] reported six cases of thigh pain but five of them resolved within 1 year. Nam et al. reported pain of any type in a young, active patient population receiving THA and surface replacement arthroplasty (SRA) [33]. They reported $10 \%$ of their population with anterior thigh pain, $8 \%$ with lateral thigh pain, and $5 \%$ with posterior thigh pain in the THA group. These numbers are not directly comparable to our study because they allowed patients to select more than one area of thigh pain on clinical surveys and also used a scale from 0 to 5 with specific descriptors of pain. Nam et al. theorized that the THA population has a higher prevalence of thigh pain than the SRA group because the patients undergoing SRA retain a more physiologic stress transfer [33]. We theorize that the thigh pain seen in our study may be related to the modulus mismatch between the stem tip and bone at the high stress subtrochanteric region of the femur and we are designing future experiments in the biomechanics laboratory to test this hypothesis. Because this is a short-term followup, there is the possibility that a subset of the thigh pain may resolve on its own similar to the Pipino et al. study, but in a later timeframe [37].

At a minimum 2-year followup, our clinical results showed no femoral components were revised for aseptic loosening. There was one femoral revision for thigh pain and one femoral revision for infection. Two patients showed stable fibrous fixation. These results are comparable or superior to other short stem reports in terms of revision frequency and HHS outcomes at short-term followup $[5-7,10,13-15,18,19,22-26,29-32,34,35$, 37-39, 41-44, 46-48, 50].

The radiographic results using this stem are comparable to conventional length cementless THA in terms of fixation and revision. The short stem and the traditional length stem demonstrated similar results in the author's (DDG) practice in terms of femoral fixation: $99 \%$ bone ingrowth for the short stem and $99 \%$ for the traditional length stem [16]. Femoral stress shielding was mild in 64\% (135 hips), moderate in $0.5 \%$ (one hip), and severe in no hips using this short stem. The conventional length stem previously reported showed mild stress shielding in 58\%, moderate in $11 \%$, and severe in $3 \%$ of hips. Kress et al. found a similar rate of stress shielding in a short femoral stem reporting $36 \%$ and $26 \%$ of hips having stress shielding in Gruen Zones 1 and 7, respectively [25]. The senior author (DDG) had consistent radiographic results with this short stem construct (Fig. 3). The metaphyseal loading of the short stem may be contributing to the preservation of the bone at the proximal end of the femur.
Younger patients reported more thigh pain than older patients. This finding corroborates the study by Nam et al. that showed a high percentage of young patients undergoing THA experiencing pain [33]. Presumably, younger patients are more active and put more stress on the implant than older, sedentary patients.

At 2- to 4-year followup of this ML taper short stem (DePuy Tri-Lock Bone Preservation Stem), patients reported considerably more thigh pain than the same surgeon's experience with a more conventional length stem. With $9 \%$ of patients describing moderate or severe thigh pain, the senior author discontinued his use of this stem. Although the thigh pain was concerning, it must be noted that patients did report excellent return to function and $99 \%$ of stems obtained bone ingrowth with minimal stress shielding. Further studies with longer followup, larger cohorts, and multiple surgeons are needed to corroborate these concerns, but in the interim, the primary surgeon has returned to a conventional length stem in primary THA.

Acknowledgments We thank Rhonda Chalus for her support with the chart review and Yubo Gao for his assistance with statistical analysis.

\section{References}

1. Adelani MA, Keeney JA, Palisch A, Fowler SA, Clohisy JC. Has total hip arthroplasty in patients 30 years or younger improved? A systematic review. Clin Orthop Relat Res. 2013;471:25952601.

2. Banerjee S, Pivec R, Issa K, Harwin SF, Mont MA, Khanuja HS. Outcomes of short stems in total hip arthroplasty. Orthopedics. 2013;36:700-707.

3. Barrack RL, Jasty M, Bragdon C, Haire T, Harris WH. Thigh pain despite bone ingrowth into uncemented femoral stems. $J$ Bone Joint Surg Br. 1992;74:507-510.

4. Bourne RB, Rorabeck CH, Ghazal ME, Lee MH. Pain in the thigh following total hip replacement with a porous-coated anatomic prosthesis for osteoarthrosis. A five-year follow-up study. J Bone Joint Surg Am. 1994;76:1464-1470.

5. Briem D, Schneider M, Bogner N, Botha N, Gebauer M, Gehrke T, Schwantes B. Mid-term results of 155 patients treated with a collum femoris preserving (CFP) short stem prosthesis. Int Orthop. 2011;35:655-660.

6. Cinotti G, Della Rocca A, Sessa P, Ripani FR, Giannicola G. Thigh pain, subsidence and survival using a short cementless femoral stem with pure metaphyseal fixation at minimum 9-year follow-up. Orthop Traumatol Surg Res. 2013;99:30-36.

7. Ender SA, Machner A, Pap G, Hubbe J, Grashoff H, Neumann HW. Cementless CUT femoral neck prosthesis: increased rate of aseptic loosening after 5 years. Acta Orthop. 2007;78:616-621.

8. Engh CA, Bobyn JD. The influence of stem size and extent of porous coating on femoral bone resorption after primary cementless hip arthroplasty. Clin Orthop Relat Res. 1988;231:728.

9. Engh CA, Massin P, Suthers KE. Roentgenographic assessment of the biologic fixation of porous-surfaced femoral components. Clin Orthop Relat Res. 1990;257:107-128. 
10. Falez F, Casella F, Panegrossi G, Favetti F, Barresi C. Perspectives on metaphyseal conservative stems. J Orthop Traumatol. 2008;9:49-54.

11. Falez F, Casella F, Papalia M. Current concepts, classification, and results in short stem hip arthroplasty. Orthopedics. 2015;38(Suppl):S6-13.

12. Gaffey JL, Callaghan JJ, Pedersen DR, Goetz DD, Sullivan PM, Johnston RC. Cementless acetabular fixation at fifteen years. A comparison with the same surgeon's results following acetabular fixation with cement. J Bone Joint Surg Am. 2004;86:257-261.

13. Ghera S, Pavan L. The DePuy Proxima hip: a short stem for total hip arthroplasty. Early experience and technical considerations. Hip Int. 2009;19:215-220.

14. Gill IR, Gill K, Jayasekera N, Miller J. Medium term results of the collum femoris preserving hydroxyapatite coated total hip replacement. Hip Int. 2008;18:75-80.

15. Goebel D, Schultz W. The Mayo cementless femoral component in active patients with osteoarthritis. Hip Int. 2009;19:206-210.

16. Goetz DD, Reddy A, Callaghan JJ, Hennessy DW, Bedard NA, Liu SS. Four- to six-year follow-up of primary THA using contemporary titanium tapered stems. Orthopedics. 2013;36:e1521-1526.

17. Gruen TA, McNeice GM, Amstutz HC. 'Modes of failure' of cemented stem-type femoral components: a radiographic analysis of loosening. Clin Orthop Relat Res. 1979;141:17-27.

18. Gustke K. Short stems for total hip arthroplasty: initial experience with the Fitmore stem. J Bone Joint Surg Br. 2012;94(Suppl A):47-51.

19. Hagel A, Hein W, Wohlrab D. Experience with the Mayo conservative hip system. Acta Chir Orthop Traumatol Cech. 2008;75:288-292.

20. Harris WH. Traumatic arthritis of the hip after dislocation and acetabular fractures: treatment by mold arthroplasty. An end-result study using a new method of result evaluation. J Bone Joint Surg Am. 1969;51:737-755.

21. Hennessy DW, Callaghan JJ, Liu SS. Second-generation extensively porous-coated THA stems at minimum 10-year followup. Clin Orthop Relat Res. 2009;467:2290-2296.

22. Hutt J, Harb Z, Gill I, Kashif F, Miller J, Dodd M. Ten year results of the collum femoris preserving total hip replacement: a prospective cohort study of seventy five patients. Int Orthop. 2014;38:917-922.

23. Kendoff DO, Citak M, Egidy CC, O'Loughlin PF, Gehrke T. Eleven-year results of the anatomic coated CFP stem in primary total hip arthroplasty. J Arthroplasty. 2013;28:1047-1051.

24. Kim YH, Kim JS, Joo JH, Park JW. A prospective short-term outcome study of a short metaphyseal fitting total hip arthroplasty. J Arthroplasty. 2012;27:88-94.

25. Kress AM, Schmidt R, Nowak TE, Nowak M, Haeberle L, Forst $\mathrm{R}$, Mueller LA. Stress-related femoral cortical and cancellous bone density loss after collum femoris preserving uncemented total hip arthroplasty: a prospective 7-year follow-up with quantitative computed tomography. Arch Orthop Trauma Surg. 2012;132:1111-1119.

26. Lazovic D, Zigan R. Navigation of short-stem implants. Orthopedics. 2006;29(Suppl):S125-129.

27. Lombardi AV Jr, Berend KR, Ng VY. Stubby stems: good things come in small packages. Orthopedics. 2011;34:e464-466.

28. Massin P, Schmidt L, Engh CA. Evaluation of cementless acetabular component migration. An experimental study. $J$ Arthroplasty. 1989;4:245-251.

29. Molli RG, Lombardi AV Jr, Berend KR, Adams JB, Sneller MA. A short tapered stem reduces intraoperative complications in primary total hip arthroplasty. Clin Orthop Relat Res. 2012;470:450-461.

30. de Cano JJ, Gordo C, Illobre JM. Early clinical results of a new conservative hip stem. Eur $J$ Orthop Surg Traumatol. 2014;24:359-363.

31. Morrey BF. Short-stemmed uncemented femoral component for primary hip arthroplasty. Clin Orthop Relat Res. 1989;249:169-175.

32. Morrey BF, Adams RA, Kessler M. A conservative femoral replacement for total hip arthroplasty A prospective study. J Bone Joint Surg Br. 2000;82:952-958.

33. Nam D, Nunley RM, Sauber TJ, Johnson SR, Brooks PJ, Barrack RL. Incidence and location of pain in young, active patients following hip arthroplasty. $J$ Arthroplasty. 2015;30:1971-1975.

34. Patel RM, Lo WM, Cayo MA, Dolan MM, Stulberg SD. Stable, dependable fixation of short-stem femoral implants at 5 years. Orthopedics. 2013;36:e301-307.

35. Patel RM, Smith MC, Woodward CC, Stulberg SD. Stable fixation of short-stem femoral implants in patients 70 years and older. Clin Orthop Relat Res. 2012;470:442-449.

36. Patel RM, Stulberg SD. The rationale for short uncemented stems in total hip arthroplasty. Orthop Clin North Am. 2014;45:19-31.

37. Pipino F, Molfetta L, Grandizio M. Preservation of the femoral neck in hip arthroplasty: results of a 13- to 17-year follow-up. $J$ Orthop Traumatol. 2000;1:31-39.

38. Pons M. Learning curve and short-term results with a short-stem CFP system. Hip Int. 2010;20(Suppl 7):S52-57.

39. Rohrl SM, Li MG, Pedersen E, Ullmark G, Nivbrant B. Migration pattern of a short femoral neck preserving stem. Clin Orthop Relat Res. 2006;448:73-78.

40. Rometsch E, Bos PK, Koes BW. Survival of short hip stems with a 'modern,' trochanter-sparing design-a systematic literature review. Hip Int. 2012;22:344-354.

41. Santori FS, Santori N. Mid-term results of a custom-made short proximal loading femoral component. J Bone Joint Surg Br. 2010;92:1231-1237.

42. Schmidutz F, Graf T, Mazoochian F, Fottner A, Bauer-Melnyk A, Jansson V. Migration analysis of a metaphyseal anchored shortstem hip prosthesis. Acta Orthop. 2012;83:360-365.

43. Sperati G, Ceri L. Total hip arthroplasty using TRI-LOCK $®$ DePuy bone preservation femoral stem: our experience. Acta Biomedicas. 2014;85:66-70.

44. Stulberg SD, Dolan M. The short stem: a thinking man's alternative to surface replacement. Orthopedics. 2008;31:885-886.

45. Stulberg SD, Patel RM. The short stem: promises and pitfalls. Bone Joint J. 2013;95(Suppl A):57-62.

46. Synder M, Drobniewski M, Pruszczynski B, Sibinski M. [Initial experience with short Metha stem implantation] [in English, Polish]. Ortop Traumatol Rehabil. 2009;11:317-323.

47. Thorey F, Hoefer C, Abdi-Tabari N, Lerch M, Budde S, Windhagen $\mathrm{H}$. Clinical results of the Metha short hip stem: a perspective for younger patients? Orthop Rev. 2013;5:e34.

48. Toth K, Mecs L, Kellermann P. Early experience with the Depuy Proxima short stem in total hip arthroplasty. Acta Orthop Belg. 2010;76:613-618.

49. van Oldenrijk J, Molleman J, Klaver M, Poolman RW, Haverkamp D. Revision rate after short-stem total hip arthroplasty: a systematic review of 49 studies. Acta Orthop. 2014;85:250-258.

50. Wittenberg RH, Steffen R, Windhagen H, Bucking P, Wilcke A. Five-year results of a cementless short-hip-stem prosthesis. Orthop Rev. 2013;5:e4. 